\title{
Microbiology Susceptibility Sponsor Defined Identifier
}

National Cancer Institute

\section{Source}

National Cancer Institute. Microbiology Susceptibility Sponsor Defined Identifier. NCI Thesaurus. Code C87942.

One or more sponsor defined characters used to identify, name, or characterize the microbiology susceptibility assessment. 